\title{
BILANGAN KROMATIK LOKASI UNTUK GALAKSI DAN HUTAN LINIER
}

\author{
ZAHARA, DES WELYYANTI, EFENDI \\ Program Studi S1 Matematika, \\ Fakultas Matematika dan Ilmu Pengetahuan Alam, Universitas Andalas, \\ Kampus UNAND Limau Manis Padang, Indonesia, \\ email : zahara.02@yahoo.com
}

\begin{abstract}
Abstrak. Misalkan $G=(V, E)$ graf terhubung dan $c$ suatu $k$-pewarnaan dari $G$. Kelas warna pada $G$ adalah himpunan titik-titik yang berwarna $i$, dinotasikan dengan $C_{i}$ untuk $1 \leq i \leq k$. Misalkan $\Pi=\left\{C_{1}, C_{2}, \cdots, C_{k}\right\}$ adalah partisi terurut dari $V(G)$ berdasarkan pewarnaan titik, maka representasi v terhadap $\Pi$ disebut kode warna dari $v$, dinotasikan dengan $c_{\Pi}(v)$. Kode warna $c_{\Pi}(v)$ dari suatu titik $v \in V(G)$ didefinisikan sebagai vektor$k$ :

$$
c_{\Pi}(v)=\left(d\left(v, C_{1}\right), d\left(v, C_{2}\right), \cdots, d\left(v, C_{k}\right)\right)
$$

dimana $d\left(v, C_{i}\right)=\min \left\{d\left(v, x: x \in C_{i}\right)\right\}$ untuk $1 \leq i \leq k$. Jika setiap titik yang berbeda di $G$ memiliki kode warna yang berbeda untuk suatu $\Pi$, maka $c$ disebut pewarnaan lokasi untuk $G$. Jumlah warna minimum yang digunakan pada pewarnaan lokasi dari graf $G$ disebut bilangan kromatik lokasi untuk $G$, dinotasikan dengan $\chi_{L}(G)$. Galaksi adalah gabungan dari graf bintang. Hutan Linier adalah gabugan dari graf lintasan. Pada tulisan ini akan dibahas bilangan kromatik lokasi untuk Galaksi dan Hutan Linier.
\end{abstract}

Kata Kunci: Kelas warna, Kode warna, Bilangan kromatik lokasi, Galaksi, Hutan Linier, Graf Bintang, Graf Lintasan

$\begin{array}{lll}\text { Diterima } & : & 29 \text { November } 2018 \\ \text { Direvisi } & : & 3 \text { Desember } 2018 \\ \text { Dipublikasikan } & : & \text { 30 Desember 2018 }\end{array}$

\section{Pendahuluan}

Teori graf merupakan salah satu cabang ilmu matematika yang sudah ada sejak 200 tahun lalu. Leonhard Euler diperkirakan yang pertama kali mempublikasikan jurnal ilmiah dalam teori graf yaitu pemecahan masalah Koningsberg. Teori graf dapat diaplikasikan ke dalam berbagai bidang. Seiring berkembangnya zaman, teori graf juga berkembang. Pada teori graf, graf-graf baru yang ditemukan juga banyak keunikan-keunikan yang dapat dibahas dengan berbagai macam operasi. Keunikan teori graf salah satunya terdapat pada kesederhanaan pokok bahasan yang dipelajarinya, karena dapat disajikan dalam titik (vertex) dan sisi (edge).

Bilangan kromatik lokasi pertama kali diperkenalkan oleh Chartand dkk (2002) [2]. Konsep ini merupakan pengembangan dari dimensi partisi dan pewarnaan graf. Pewarnaan titik pada graf adalah pemberian warna untuk setiap titik pada graf dengan syarat setiap titik yang bertetangga harus memiliki warna yang berbeda. 
Jumlah warna minimum yang digunakan untuk pewarnaan titik pada graf $G$ disebut bilangan kromatik lokasi yang dinotasikan dengan $\chi_{L}(G)$.

Bilangan kromatik lokasi untuk beberapa graf yang sudah diketahui misalnya, untuk graf lintasan $P_{n}$ untuk $n \geq 3$ diperoleh $\chi_{L}\left(P_{n}\right)=3$. Bilangan kromatik lokasi untuk graf lingkaran, yaitu $\chi_{L}\left(C_{n}\right)=3$ untuk $n$ ganjil sedangkan $\chi_{L}\left(C_{n}\right)=4$ untuk $n$ genap.

Berdasarkan penelitian Welyyanti dkk. pada tahun 2014 [5], menghasilkan suatu teori tentang perluasan pengertian bilangan kromatik lokasi suatu graf yang dapat diaplikasikan pada semua jenis graf termasuk pada gabungan graf yang disebut galaksi dan hutan linier.

\section{Bilangan Kromatik Lokasi}

Graf $G$ adalah pasangan himpunan $V$ dan $E$, dituliskan $G=(V, E)$, dimana $V$ adalah suatu himpunan titik (vertex) yang tidak kosong dan $E$ adalah himpunan sisi (edge) yang terdiri dari pasangan terurut dari titik-titik berbeda dari $V$. Misalkan $V=\left\{v_{1}, v_{2}, \cdots, v_{n}\right\}$ adalah himpunan titik yang berisi $n$ titik di $G$ dan $E=\left\{e_{1}, e_{2}, \cdots, e_{m}\right\}$ adalah himpunan sisi yang berisi $m$ sisi di $G$. secara umum, untuk menotasikan sisi dapat ditulis dengan $v_{i} v_{j}$ atau $v_{j} v_{i}$. Graf lintasan $\left(P_{n}\right)$ adalah graf dengan $n$ titik dan $n-1$ sisi, dengan titik-titiknya adalah $v_{1}, v_{2}, \cdots, v_{n}$ dan sisi-sisinya adalah $v_{1} v_{2}, v_{2} v_{3}, \cdots, v_{n-1} v_{n}$, dinotasikan dengan $P_{n}$. Gabungan graf lintasan disebut Hutan Linear. Graf Bintang $\left(K_{1, n}\right)$ adalah suatu graf terhubung yang mempunyai satu titik berderajat $n$ yang disebut pusat dan titik lainnya berderajat satu. Gabungan graf bintang disebut Galaksi.

Bilangan kromatik (chromatic number) dari graf $G$ adalah bilangan asli terkecil $k$ sedemikian sehingga $G$ mempunyai suatu pewarnaan- $k$ titik sejati. Bilangan kromatik dari $G$ dinotasikan dengan $\chi(G)$. Misalkan $\chi(G)=k$, ini berarti titik-titik di $G$ paling kurang diwarnai dengan $k$ warna dan tidak dapat diwarnai dengan $k-1$ warna. jika titik-titik di $G$ diwarnai dengan $k$ warna maka tidak ada titik yang bertetangga mempunyai warna yang sama.

Misalkan $C_{i}$ himpunan titik yang diberi warna $i$ dengan $1 \leq i \leq k$, disebut kelas warna, dimana $\Pi=\left\{C_{1}, C_{2}, \cdots, C_{k}\right\}$ adalah himpunan yang terdiri dari kelas-kelas warna dari $V(G)$. Titik $v \in C_{i}$ disebut titik dominan jika $d\left(v, C_{i}\right)=0$ dan $d\left(v, C_{j}\right)=1$ untuk $i \neq j$. Kode warna $c_{\Pi}(v)$ dari $v$ adalah $k$-pasang terurut

$$
\left(d\left(v, C_{1}\right), d\left(v, C_{2}\right), \cdots, d\left(v, C_{k}\right)\right),
$$

dimana $d\left(v, C_{i}\right)=\min \left\{d(v, x): x \in C_{i}\right\}$, untuk $1 \leq i \leq k$. Jika setiap titik di $G$ memiliki kode warna yang berbeda, maka $c$ disebut pewarnaan lokasi dari $G$. Banyaknya warna minimum yang digunakan sedemikian sehingga $G$ mempunyai pewarnaan lokasi disebut bilangan kromatik lokasi dari $G$ dan dinotasikan dengan $\chi_{L}(G)$.

Chartrand dkk. (2002) telah memberikan teorema dasar bilangan kromatik lokasi suatu graf. Teorema tersebut dijelaskan pada teorema-teorema di bawah ini. Definisikan $N(v)$ sebagai himpunan yang berisi semua titik yang menjadi tetangga dari $v$. 
Teorema 2.1. [3] Misal c adalah suatu pewarnaan lokasi pada graf terhubung $G$. Jika $u$ dan $v$ adalah dua titik pada graf $G$ sedemikian sehingga $d(u, w)=d(v, w)$ untuk setiap $w \in V(G) \backslash\{u, v\}$, maka $c(u) \neq c(v)$. Dalam hal khusus, jika $u$ dan $v$ adalah titik-titik yang tidak bertetangga di $G$ sedemikian sehingga $N(u)=N(v)$, $\operatorname{maka} c(u) \neq c(v)$.

Bukti. Misalkan $c$ adalah suatu pewarnaan lokasi pada graf terhubung $G$ dan misalkan $\Pi=\left(C_{1}, C_{2}, \cdots, C_{k}\right)$ adalah partisi dari titik-titik $G$ ke dalam kelas warna $C_{i}$. Untuk suatu titik $u, v \in V(G)$, andaikan $c(u)=c(v)$ sedemikian sehingga titik $u$ dan $v$ berada dalam kelas warna yang sama, misal $C_{i}$ dari $\Pi$. Akibatnya, $d\left(u, C_{i}\right)=d\left(v, C_{i}\right)=0$. Karena $d(u, w)=d(v, w)$ untuk setiap $w \in V(G) \backslash u, v$ maka $d\left(u, C_{j}\right)=d\left(v, C_{j}\right)$ untuk setiap $j \neq i, 1 \leq j \leq k$. Akibatnya, $c_{\Pi}(u)=c_{\Pi}(v)$ sehingga $c$ bukan pewarnaan lokasi. Dengan demikian, $c_{\Pi}(u) \neq c_{\Pi}(v)$.

Akibat 2.2. [3] Jika $G$ adalah suatu graf terhubung yang memuat suatu titik yang bertetangga dengan $k$ daun di $G$, maka $\chi_{L}(G) \geq k+1$.

Bukti. Misalkan $v$ adalah suatu titik yang bertetangga dengan $k$ daun $x_{1}, x_{2}, \cdots$, $x_{k}$ di $G$. Dari Teorema 2.1 setiap pewarnaan lokasi dari G mempunyai warna berbeda untuk setiap $x_{i}, i=1,2, \cdots, k$. Karena $v$ bertetangga dengan semua $x_{i}$, maka $v$ harus mempunyai warna yang berbeda dengan semua daun $x_{i}$. Akibatnya, $\chi_{L}(G) \geq k+1$.

Misalkan $H$ adalah graf tak terhubung dan $c$ adalah pewarnaan $k$-titik pada $H$ yang menginduksi partisi $\Pi=\left\{C_{1}, C_{2}, \cdots, C_{k}\right\}$ dari $V(H)$. Kode warna dari titik $v \in V(H)$ adalah $\left(d\left(v, C_{1}\right), d\left(v, C_{2}\right), \cdots, d\left(v, C_{k}\right)\right)$ dengan $d\left(v, C_{i}\right)=\min$ $\left\{d(v, x): x \in C_{i}\right\}$ dan $d\left(v, C_{i}\right) \leq \infty$ untuk $1 \leq i \leq k$. Pewarnaan $c$ dikatakan pewarnaan lokasi- $k$ jika semua kode warna dari titik-titik pada $H$ berbeda. Bilangan kromatik lokasi dari graf tak terhubung $(\mathbf{H})$ dinotasikan dengan $\chi_{L}^{\prime}(H)$, yaitu bilangan terkecil $k$ sedemikian sehingga $H$ mempunyai $k$ pewarnaan lokasi. Jika tidak ada nilai $k$ yang memenuhi maka $\chi_{L}^{\prime}(H)=\infty[5]$. Bilangan kromatik lokasi untuk graf tak terhubung dapat bernilai hingga dan tak hingga.

Teorema 2.3. Untuk setiap $i$, misalkan $G_{i}$ adalah graf terhubung dan misalkan $H=\bigcup_{i=1}^{m} G_{i}$. Jika $\chi_{L}^{\prime}(H)<\infty$, maka $q \leq \chi_{L}^{\prime}(H) \leq r$, dimana $q=\max \left\{\chi_{L}\left(G_{i}\right)\right.$ : $i \in[1, m]\}$ dan $r=\min \left\{\left|V\left(G_{i}\right)\right|: i \in[1, m]\right\}$.

Bukti. Karena $q=\max \left\{\chi_{L}\left(G_{i}\right): i \in[1, m]\right\}$, terdapat bilangan bulat $k \in[1, m]$ sedemikian sehingga $\chi_{L}\left(G_{k}\right)=q$. Ini berarti setiap pewarnaan lokasi dari graf $H$ haruslah paling sedikit $q$ warna pada setiap komponen dari $H$. Jadi $\chi_{L}^{\prime}(H) \geq q$. Selanjutnya akan ditunjukkan batas atas dari $\chi_{L}^{\prime}(H)$. Karena $r=\min \left\{\left|V\left(G_{i}\right)\right|\right.$ : $i \in[1, m]\}$, terdapat bilangan bulat $k \in[1, m]$ sedemikian sehingga $\chi_{L}\left(G_{k}\right)=r$. Ini berarti setiap pewarnaan lokasi dari $H$ harus memiliki paling banyak $r$ warna pada setiap komponen dari $H$. Jadi $\chi_{L}^{\prime}(H) \leq r$. 


\section{Bilangan Kromatik Lokasi Untuk Galaksi Dan Hutan Linier}

Pada Teorema 3.1 berikut diperoleh bilangan kromatik lokasi untuk galaksi dan hutan linier.

Teorema 3.1. Misalkan $H=\bigcup_{i=1}^{t} K_{1, n_{i}}$ dan $n_{i} \geq 2$, maka

$$
\chi_{L}^{\prime}(H)= \begin{cases}n+1, & \text { untuk } n_{1}=n_{2}=\cdots=n_{t}=n \text { dan } t=n+1 \\ \infty, & \text { lainnya }\end{cases}
$$

Bukti. Berdasarkan Teorema 3, $\chi_{L}(H) \geq q$, dengan $q=\max \left\{\chi_{L}\left(K_{1, n_{i}}\right): i \in\right.$ $[1, t]\}$. Karena $\chi_{L}\left(K_{1, n_{i}}\right)=n_{i}+1$, maka $q=\max \left\{n_{i}+1: i \in[1, t]\right\}$. Jika terdapat $j$ sedemikian sehingga $n_{j}<q$, maka $\chi_{L}^{\prime}(H)=\infty$.

Selanjutnya untuk $n_{i}=n$ untuk setiap $i$ akan ditunjukkan bahwa $\chi_{L}^{\prime}(H)=n+1$. Misalkan $H=\bigcup_{i=1}^{t} K_{1, n}$ dan $V(H)=\left\{x_{i}: i \in[1, t]\right\} \bigcup_{i=1}^{t} A_{i}$, dengan $x_{i}$ adalah titik akar dan $A_{i}$ adalah himpunan dari titik-titik akhir pada $K_{1, n_{i}}$. Selanjutnya, definisikan suatu pewarnaan $c: V(H) \rightarrow\{1,2, \cdots, n+1\}$ sehingga

$$
\begin{aligned}
c\left(x_{i}\right) & =i, \\
c\left(A_{i}\right) & =[1, n+1] \backslash\{i\} .
\end{aligned}
$$

Misalkan $\Pi=\left\{C_{1}, C_{2}, \cdots, C_{n+1}\right\}$ adalah partisi dari $V(H)$ berdasarkan $c$, dimana $C_{i}$ adalah himpunan semua titik penerima warna $i$. Selanjutnya akan ditunjukkan bahwa kode warna dari semua titik-titik berbeda. Misalkan $u$ dan $v$ adalah dua titik yang berbeda dengan $c(u)=c(v)$. Jika $u=x_{i}$ dan $v \in A_{j}$ untuk $i, j \in[1, t]$, maka $d\left(u, C_{i+2 \bmod (n+1)}\right)=1$ dan $d\left(v, C_{i+2 \bmod (n+1)}\right)=2$. Oleh sebab itu, $c_{\Pi}(u) \neq c_{\Pi}(v)$.

Selanjutnya, asumsikan $u \in A_{i}$ dan $v \in A_{j}$ dimana $i \neq j$ dan $i, j \in[1, t]$. Maka $d\left(u, C_{i}\right)=1$ dan $d\left(v, C_{i}\right)=2$. Oleh sebab itu, $c_{\Pi}(u) \neq c_{\Pi}(v)$. Akibatnya semua titik-titik mempunyai kode warna yang berbeda, sehingga $\chi_{L}^{\prime}(H)=n+1$.

Teorema 3.2. Misalkan $H=\bigcup_{i=1}^{t} P_{n_{i}}, r=\min \left\{n_{i}: i \in[1, t]\right\}$. Jika $\chi_{L}^{\prime}(H)<\infty$, maka $3 \leq \chi_{L}^{\prime}(H) \leq r$. Khususnya $\chi_{L}^{\prime}(H)=3$, hanya dipenuhi oleh $t=1,2$, atau 3 .

Bukti. Berdasarkan Teorema 3, karena $q=3$, maka $\chi_{L}^{\prime}(H) \geq 3$ dan $\chi_{L}^{\prime}(H) \leq r$. Misalkan $V(H)=V\left(P_{n_{1}}\right) \cup V\left(P_{n_{2}}\right) \cup V\left(P_{n_{3}}\right)$, dengan $V\left(P_{n_{1}}\right)=\left\{x_{1}, x_{2}, \cdots, x_{n_{1}}\right\}$, $V\left(P_{n_{2}}\right)=\left\{y_{1}, y_{2}, . ., y_{n_{2}}\right\}, V\left(P_{n_{3}}\right)=\left\{z_{1}, z_{2}, . ., z_{n_{3}}\right\}$. Sekarang, pandang suatu pewarnaan $c: V(H) \rightarrow\{1,2,3\}$ sedemikian sehingga

$$
\begin{aligned}
& c\left(x_{1}\right)=c\left(y_{2}\right)=c\left(z_{1}\right)=1, \\
& c\left(x_{2}\right)=c\left(y_{1}\right)=c\left(z_{3}\right)=2, \\
& c\left(x_{3}\right)=c\left(y_{3}\right)=c\left(z_{2}\right)=3,
\end{aligned}
$$

untuk $k \in\left[4, n_{1}\right], l \in\left[4, n_{2}\right], m \in\left[4, n_{3}\right]$, didefinisikan

$$
c\left(x_{k}\right)= \begin{cases}2, & \text { jika } k \text { genap } \\ 3, & \text { jika } k \text { ganjil }\end{cases}
$$




$$
\begin{gathered}
c\left(y_{l}\right)= \begin{cases}1, & \text { jika } l \text { genap } \\
3, & \text { jika } l \text { ganjil }\end{cases} \\
c\left(z_{m}\right)= \begin{cases}3, & \text { jika } m \text { genap } \\
2, & \text { jika } m \text { ganjil }\end{cases}
\end{gathered}
$$

Misalkan $\Pi=\left\{C_{1}, C_{2}, C_{3}\right\}$ adalah partisi oleh $c$. Selanjutnya, akan ditunjukkan bahwa kode warna dari semua titik berbeda. Jelas bahwa

$$
\begin{aligned}
& c_{\Pi}\left(x_{1}\right)=(0,1,2), c_{\Pi}\left(x_{2}\right)=(1,0,1), c_{\Pi}\left(x_{3}\right)=(2,1,0), \\
& c_{\Pi}\left(y_{1}\right)=(1,0,2), c_{\Pi}\left(y_{2}\right)=(0,1,1), c_{\Pi}\left(y_{3}\right)=(1,2,0), \\
& c_{\Pi}\left(z_{1}\right)=(0,2,1), c_{\Pi}\left(z_{2}\right)=(1,1,0), c_{\Pi}\left(z_{3}\right)=(2,0,1) .
\end{aligned}
$$

Untuk $k \in\left[4, n_{1}\right]$ diperoleh $c_{\Pi}\left(x_{k}\right)=(k-1,0,1)$ jika $k$ genap dan $c_{\Pi}\left(x_{k}\right)=(k-$ $1,1,0)$ jika $k$ ganjil. Untuk $l \in\left[4, n_{2}\right]$ diperoleh $c_{\Pi}\left(y_{l}\right)=(0, l-1,1)$ jika $l$ genap dan $c_{\Pi}\left(y_{l}\right)=(1, l-1,0)$ jika $l$ ganjil. Untuk $m \in\left[4, n_{3}\right]$ diperoleh $c_{\Pi}\left(z_{m}\right)=(m-1,1,0)$ jika $m$ genap dan $c_{\Pi}\left(z_{m}\right)=(m-1,0,1)$ jika $m$ ganjil. Karena semua titik memiliki kode warna yang berbeda, akibatnya, $\chi_{L}^{\prime}(H) \leq 3$. Jika $t \geq 2$, maka batas pewarnaan $c$ disesuaikan dengan komponen. Jadi $\chi_{L}^{\prime}(H)=3$ untuk $t=1,2$, atau 3.

\section{Kesimpulan}

Pada makalah ini telah dibahas bilangan kromatik lokasi untuk galaksi dan hutan linier. Galaksi $H=\bigcup_{i=1}^{t} K_{1, n_{i}}$, dimana $K_{1, n_{i}}$ adalah koleksi bintang, dan hutan linier $H=\bigcup_{i=1}^{t} P_{n_{i}}$ dimana $P_{n_{i}}$ adalah koleksi lintasan, untuk $i \in[1, t]$.

Bilangan kromatik lokasi untuk galaksi $H=\bigcup_{i=1}^{t} K_{1, n_{i}}$ untuk $i \in[1, t]$ dan $n_{i} \geq 2$ adalah

$$
\chi_{L}^{\prime}(H)= \begin{cases}n+1, & \text { untuk } n_{1}=n_{2}=\cdots=n_{t}=n \text { dan } t=n+1, \\ \infty, & \text { lainnya. }\end{cases}
$$

Bilangan kromatik lokasi untuk hutan linier $H=\bigcup_{i=1}^{t} P_{n_{i}}$ khususnya $\chi_{L}^{\prime}(H)=3$, hanya dipenuhi oleh $t=1,2$, atau 3 .

\section{Ucapan Terima kasih}

Terima kasih kepada bapak Prof. Dr. Syafrizal Sy, bapak Budi Rudianto, M.Si, dan bapak Yudiantri Asdi, M.Sc, selaku dosen penguji, yang telah memberikan kritik dan saran dalam penulisan makalah ini.

\section{Daftar Pustaka}

[1] Asmiati and E.T. Baskoro, 2012. Characterizing All Graphs Containing Cycles With Locating-Chromatic Number 3. AIP Conf. Proc. 321 - 357. 
92 Zahara $d k k$

[2] Bondy, J.A dan Murty, U.S.R. 1976. Graph Theory with Application. London: The Macmillan Press LTD.

[3] Chartrand, G., dkk. 2002 The locating-chromatic number of a graph. Bull. Inst. Combin. Appl. 36: $89-101$.

[4] Chartrand, G.,dkk. 2003. Graph of Order n With Locating-Chromatic Number n-1. Discrete Math. 269: $65-79$.

[5] Welyyanti, D., Baskoro, E.T, Simanjuntak, R., Utunggadewa, S 2014 The Locating-Chromatic Number of Disconnected Graphs. Far East Journal of Mathematical Science. 94(2): 169 - 182. 